\title{
EXPERIMENTAL AND NUMERICAL STUDY OF WAX DEPOSITION IN A LABORATORY-SCALE PIPE SECTION UNDER WELL-CONTROLLED CONDITIONS
}

\section{Annex 1 - Radial temperature profiles in the annular deposition test section}

Measured and predicted temperature profiles in the annular gap were presented in Figure 12. Although commented in the text, the comparisons of the measured profiles with the purely-conductive logarithmic solution within the deposit region were not presented in order not to overcrowd the figure. This comparison is presented here in Figure A1.

Each figure associated with one value of the Reynolds number, presents the measured profile with symbols, the purely-conductive logarithmic profile as a solid line, and the profile

obtained from the numerical simulations as dashed lines. Profiles are presented for times of 5 minute, 1 and 4 hours after the initiation of the deposition process. The position of the deposit interface is also presented as a horizontal line for reference purposes.

The conductive logarithmic profiles were obtained by the solution of the conduction equation for the deposit in cylindrical coordinates, having the measured internal wall and deposit interface temperatures as boundary conditions, leading to,

$$
\frac{T(r)-T_{w}}{T_{w}-T_{\infty}}=\frac{\ln \left(r / r_{i n t}\right)}{\ln \left(r_{\text {int }} / r_{\text {ext }}\right)}
$$



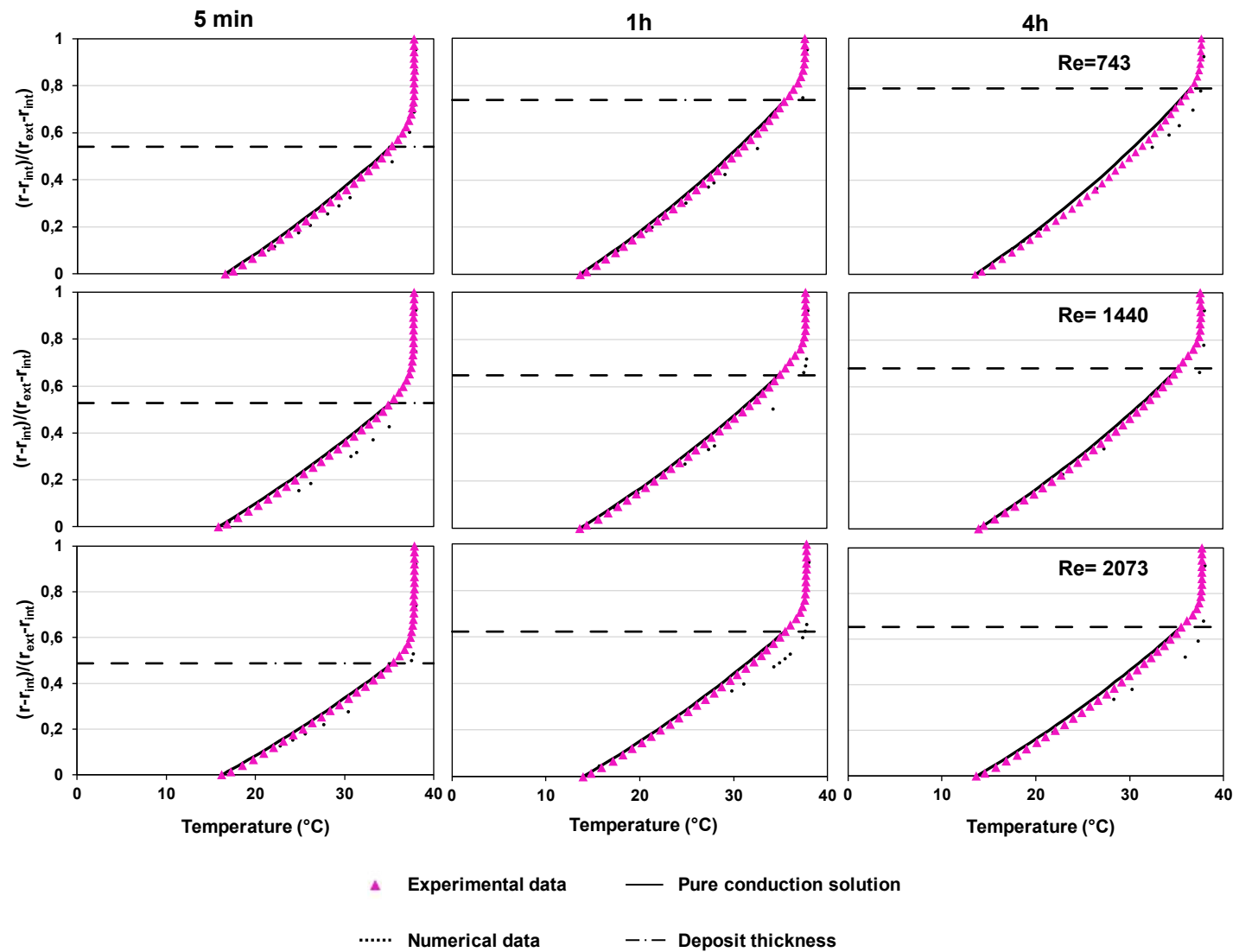

Figure A1 - Comparison of the measured temperature profiles with the purely-conductive solution (equation A1) and the numerically predicted profiles. Each row of figures represents a Reynolds number value (743, 1440 or 2073), while each column represents a given time after the innitiation of deposition (5 minutes, 1 hour or 4 hours). 